\title{
A REFLEXIVIDADE NOS DISCURSOS IDENTITÁRIOS DA CAPOEIRA'
}

\author{
MS. JULIANA AZEVEDO DE ALMEIDA \\ Professora Escola Superior São Francisco de Assis (ESFA), GEPCA (Grupo de Estudos \\ sobre Cultura e Africanidades) (Vitória - Espirito Santo - Brasil) \\ E-mail: julazal@yahoo.com.br \\ DR. OTÁVIO TAVARES \\ Professor Associado do Centro de Educação Física e Desportos (CEFD) da Universidade \\ Federal do Espírito Santo (UFES), ARETE (Centro de Estudos Olímpicos) \\ (Vitória - Espirito Santo - Brasil) \\ E-mail: otaviotavares@pq.cnpq.br
}

\begin{abstract}
DR. ANTONIO JORGE GONÇALVES SOARES
Professor Associado da Faculdade de Educação da Universidade Federal do Rio de Janeiro, GESED

(Grupo de Estudos dos Sistemas Educacionais), Doutorado na Universidade Gama Filho

(Rio de Janeiro - Rio de Janeiro - Brasil)

E-mail: antoniojsoares@pq.cnpq.br
\end{abstract}

\section{RESUMO}

A identidade é contingente e relacional. É definida sempre em comparação com um "outro" através de marcações simbólicas e sociais. Partindo dessa premissa, este estudo busca demonstrar que as narrativas identitárias da Capoeira atual se estruturam por "processos reflexivos". Utilizando métodos etnográficos, os discursos identitários de um grupo de capoeira foram comparados aos discursos acadêmicos sobre essa prática. Concluímos que as narrativas identitárias da Capoeira se estruturam por meio de uma reflexividade incompleta que transparece o processo de modernização da sociedade e, consequentemente, de ressurgimento do nacional.

PALAVRAS-CHAVE: Capoeira; identidade; reflexividade; Educação Física.

I. O trabalho recebeu apoio financeiro da Fundação de Apoio à Ciência e Tecnologia do ES (FAPES), edital $0165 / 2006$ e processo $35416971 / 2006$. 
Debater a identidade da Capoeira é uma tarefa complexa, pois, atualmente, as práticas culturais, bem como os sujeitos que as constroem, não se enquadram em definições únicas e cristalizadas como era feito outrora. Hall (2005) esclarece que esses estão "fragmentados" e, nesse sentido, adquirem novas identidades diante das rápidas, constantes e permanentes mudanças das sociedades contemporâneas.

A identidade é contingente e relacional; ela é definida sempre em comparação com um "outro", através de marcações simbólicas e sociais (WOODWARD, 2000). Na modernidade tardia, que é frequentemente transpassada por divisões e contradições, os indivíduos passaram a assumir diferentes posições, isto é, identidades. Nesse contexto, as antigas estruturas identitárias, que estabilizavam o mundo social, se enfraqueceram, caracterizando o que muitos estudiosos têm chamado de "crise de identidade" (HALL, 2005, p.7). Essa crise acontece porque as tradições, que firmavam os indivíduos e os grupos em "certezas", perdem sentido frente aos "processos reflexivos" da modernidade (GIDDENS, 2002).

Podemos dizer que a "reflexividade" é um mecanismo de circulação de informações especializadas e "leigas" sobre uma determinada prática social que está sendo constantemente reformulada, por meio dos novos conhecimentos adquiridos, por seus atores sociais. Esse processo de transformação contínua acontece por meio dos mecanismos de desencaixe ${ }^{2}$ da era moderna. Esses mecanismos

[...] atuam desqualificando muitos aspectos das atividades cotidianas. Essa desqualificação não é simplesmente um processo em que especialistas técnicos se apropriam do conhecimento cotidiano (uma vez que muitas das vezes há características imponderáveis ou ardentemente disputadas em seus campos de especialização); e nem é um processo unidirecional, porque a informação especializada, como parte da reflexividade da modernidade, é de uma forma ou de outra constantemente apropriada pelos leigos (GIDDENS, 2002, p. 27).

Assim, a reflexividade, a partir de Giddens, deve ser tomada como um conceito que ajuda a compreender o fenômeno dos discursos sobre a Capoeira, e não um substantivo em si.

A preocupação com a homogeneização cultural e com os riscos gerados pela modernidade acaba por fortalecer vínculos locais e nacionais. Hoje, um dos mais eficazes dispositivos identitários é a cultura nacional. Ela é formada fundamentalmente por discursos simbólicos, que estão em constante disputa interna, sendo "unificada"

2. 'Desencaixe" é o 'deslocamento' das relações sociais de contextos locais de interação e sua reestruturação sem fronteiras de tempo-espaço (GIDDENS, 2002). 
por alguns pontos de interseção afirmados dentro de uma estrutura maior de poder cultural. Dessa forma, as culturas nacionais "costuram" as diferenças culturais numa única identidade, neste caso, a nação (HALL, 2005).

Inserida nesse contexto e carregando a marca de "autenticamente brasileira", a Capoeira, por meio de seus atores sociais, apropria-se de estratégias discursivas e as interliga com práticas da modernidade para construir sua legitimidade e manter-se "viva" diante da dinâmica do universo social (SCHNEIDER, 2004). Contudo, essa ligação não é feita sem lutas e conflitos. Devemos lembrar que neste campo há segmentações de práticas e identidades marcadas por estilos e escolas que competem entre si. Observamos um processo contraditório e mesmo ambíguo, no qual a busca pela "verdadeira Capoeira "e pela sua "evolução" surge como ideais conciliados no plano discursivo, apesar de indicarem, no plano lógico dos discursos identitários, movimentos opostos.

Em artigo publicado na Revista Brasileira de Ciências do Esporte (RBCE), Almeida, Tavares e Soares (2008) analisaram os discursos acadêmicos sobre a Capoeira no referido periódico. Por meio desse trabalho percebemos como os discursos dos praticantes ${ }^{3}$ apresentam continuidades e rupturas com os discursos acadêmicos veiculados na RBCE entre 1989 e 2006.

Diante disso, este artigo objetiva identificar e analisar alguns mecanismos que estruturam as narrativas identitárias sobre Capoeira a partir de seus diferentes atores na atualidade, no intuito de contribuir para a compreensão dos modos como os mesmos afirmam o seu pertencimento ao nacional e, com efeito, constroem a "narrativa da nação." Nossa hipótese é que as narrativas que estruturam a(s) identidade(s) da Capoeira no cenário atual são elaboradas e legitimadas dialogicamente, através de processos reflexivos entre o campo de produção intelectual sobre o tema e o campo da prática.

\section{MÉTODO}

Utilizamos a etnografia como método de pesquisa. Um pesquisador inseriu-se num grupo de Capoeira Contemporânea, ${ }^{4}$ selecionado/escolhido por seu caráter

3. Temos conhecimento que grande parte da produção acadêmica sobre a Capoeira é elaborada por seus praticantes, todavia, para fins didáticos, neste texto vamos nos referir aos atores sociais da Capoeira como "praticantes" e "acadêmicos". Os praticantes são aqueles que treinam e/ou jogam Capoeira (também chamados de Capoeiras ou capoeiristas); os acadêmicos são os sujeitos que possuem produções acadêmicas sobre essa atividade corporal.

4. Atualmente, é difícil definir estilos na Capoeira, mas os mais evidenciados são: a Capoeira Angola, a Capoeira Regional e a Capoeira Contemporânea. A Capoeira Contemporânea seria uma mistura dos dois primeiros estilos conjugados com elementos característicos das práticas corporais 
renomado e tradicional, durante sete meses. Os dados foram coletados a partir da observação participante (treinando, participando das rodas, dos momentos de lazer e de espaços "alternativos" - como o grupo de e-mail) e através de entrevistas semiestruturadas.

Considerando as características da investigação, um problema que mereceu nossa atenção foi aquele do distanciamento, uma questão crítica para a etnografia. Sendo assim, o pesquisador de campo permaneceu em um exercício constante de "estranhar o familiar" (VELHO, 2003, p. 15), já que é praticante dessa atividade. Desse modo, para compreendermos e empreendermos melhor a coleta de dados, apropriamo-nos dos conceitos e técnicas etnográficas de White (2005) e Wacquant (2002).

Após esta fase, analisamos e interpretamos as informações registradas em diário de campo e as contrastamos com os discursos sobre Capoeira veiculados na RBCE. Nossa observação foi guiada no sentido de observar como ideologias e mitos que circulam nos diferentes campos, o nativo e o acadêmico, podem formar o discurso da Capoeira.

\section{A REFLEXIVIDADE ENTRE OS DISCURSOS}

O estudo de campo foi realizado no grupo de Capoeira Humaitá, ${ }^{5}$ associação fundada em Brasília no ano de 1972. Desde o seu surgimento, o Humaitá esteve ligado às instituições escolares. Cabe dizer que essa foi uma estratégia encontrada pelo mestre fundador, já que ele via as escolas como espaço privilegiado para a ascensão social do grupo (LUCAS, 2002).

À medida que os espaços de atuação do grupo Humaitá aumentavam, seu estilo se modificava para atender às demandas da "clientela" (LUCAS, 2002). O grupo estruturou um sistema de graduação ${ }^{6}$ pautado na relação entre as "fases sociais que marcaram a vida do negro no Brasil com os domínios de irradiação dos Orixás do Candomblé e da Umbanda" (FALCÃO; VIEIRA, 1997, p.50). Embora os mestres do grupo destaquem que essa orientação é puramente filosófica, nos chamou a atenção a mensagem transmitida. Essa mensagem exalta uma pureza étnica da Capoeira, seu

modernas. Devemos dizer que nem todos os atores sociais da Capoeira intitulam esse estilo ou se autodenominam como "Capoeira Contemporânea", mas neste estudo utilizaremos esse nome para designá-lo.

5. O grupo investigado não nos autorizou a identificá-lo, mas podemos mencionar que ele se localiza em uma cidade de médio porte da Região Sudeste do Brasil. Utilizamos nomes fictícios, tanto para o grupo quanto para os seus praticantes.

6. No Humaitá, o sistema de graduação é composto de cordas de algodão. 
caráter sacro, e atribui uma autenticidade mais "africanizada" a esse grupo. Vemos que essa fundamentação se baseia nos mitos que narram a história da Capoeira, os quais também estão presentes em alguns discursos acadêmicos veiculados na RBCE.

Vale ressaltar que no mundo da Capoeira a função de mestre ultrapassa o simples ato de ensinar e assume, na maioria dos casos, uma representação quase paterna. Preservando algumas ideias do mestre fundador - de educar pela Capoeira, de aproximar os praticantes dos estudiosos do tema, de ingressar nas instituições de ensino, etc. -, o grupo Humaitá se expandiu e adquiriu características peculiares.

Mestre Magno é o responsável pelo núcleo do grupo Humaitá que foi locus deste estudo. Além disso, na época da pesquisa, Magno também era professor universitário, mestrando, presidente do Conselho de Mestres do grupo e coordenador dos núcleos do Humaitá nos Estados Unidos e na Suíça. Levando em conta os espaços em que o mestre transita e analisando seu comportamento no grupo Humaitá, reconhecemos ser Magno um importante mediador entre o campo acadêmico e o prático da Capoeira.

Por entender a Capoeira como atividade que ultrapassa os gestos corporais, Magno procura disponibilizar aos seus alunos o máximo de conhecimentos e informações relacionados a essa manifestação cultural. Não obstante, ainda que o mestre considere importante a aquisição e a troca de conhecimentos, nem sempre os capoeiristas se interessam em adquirir essas informações ou utilizá-las, efetivamente, nos espaços sociais onde atuam.

Isso acontece porque dentro de um grupo existem variadas visões de mundo e estilos de viver, e diversificadas representações sobre a Capoeira. Essas diferenças são significantes e promovem frequentes conflitos pessoais e políticos no Humaitá. Em momentos de tensão, a figura do mestre é essencial para manter a coesão entre os membros, articulando os diferentes interesses ou, em casos mais extremos, colocando algumas determinações que, até mesmo por serem impostas, são respeitas pela maioria. As próprias tradições da Capoeira dão respaldo a esses líderes na tarefa de "fazer-se acreditar" e, assim, poder exercer a sua autoridade. Cabe ressaltar que nessas tradições se articulam a concepção de liderança carismática e autoritária, tão comum no espírito patriarcal da sociedade brasileira (TELLES, 1993). Sendo assim, vemos que o mestre é o "articulador" entre as várias identidades existentes, e é a figura essencial para que o grupo se mantenha coeso e ativo.

Analisando os documentos do grupo (seu estatuto e código de ética), verificamos que a articulação entre a prática da Capoeira e as produções acadêmicas sobre o tema é uma das metas de legitimação do grupo, e não somente uma orientação de alguns mestres. Nesta associação, a aquisição de informaç̧ão é incentivada não apenas pela leitura de revistas sobre Capoeira, mas, principalmente, pelo estímulo à leitura de estudos acadêmicos e à pesquisa. 
Além dessa conexão formalizada, existem instrumentos que articulam com muito mais força as ideias veiculadas nos campos em questão. Por serem relembrados cotidianamente, e por serem representados por símbolos, esses instrumentos passam a ter significados que não são tão compreendidos por todos, mas produzem sentimentos que conectam os diferentes indivíduos a um forte pertencimento ao grupo, e também à Capoeira.

Atualmente, o "hino do grupo" é um desses instrumentos. Diversas associações de Capoeira - acreditamos que a maioria delas - possuem uma música oficial. O estatuto do Humaitá deixa claro que o seu hino deve ser estimulado em todos os núcleos. Na experiência de campo, pudemos observar que o hino é uma ferramenta poderosa de afirmação identitária do grupo. A eficácia identitária não acontece somente quando os integrantes estão em contato com outro grupo de Capoeira, mas também a cada vez que é cantado na roda.

Cantar o hino é declarar uma determinada cumplicidade. Ao ser entoado, o hino refaz na memória dos integrantes as ideologias e os sentimentos que os vinculam a esta, e não a outra "comunidade". Por meio dele, os integrantes do grupo pesquisado afirmam que a Capoeira que eles praticam é, de certo modo, diferente das "outras", e é uma "luta leal": "Me ensinou a bater no pandeiro, a tocar o berimbau, me ensinou a fazer dessa luta, uma luta leal" (trecho extraído do hino do grupo Humaitá).

Cabe esclarecer que a palavra "lealdade" tornou-se uma importante marca da identidade do Humaitá. Ela é cantada, estampada em camisas, e declarada em discursos formais e informais. Além disso, seu significado indefinido proporciona a articulação de ideias que são produzidas em diferentes campos onde a Capoeira é discutida.

Mestre Magno crê que essa "lealdade" se manifesta na fidelidade que o capoeirista deve ter com a cultura; no respeito aos "saberes populares"; no papel desempenhado na luta por uma sociedade mais democrática. Magno transfere para a palavra "lealdade" os ideais que dão significado aos seus projetos para a Capoeira, planos que se confundem com ideais de uma sociedade que se pretende justa e igualitária. No entanto, a estrutura hierarquizada da Capoeira vai, por vezes, de encontro às relações menos verticalizadas de uma vida democrática.

É importante ressaltar que existem significativas semelhanças entre as ideias do mestre e alguns discursos sobre a Capoeira veiculados na RBCE. Confirmando o tratamento dado por Castro Júnior à roda de Capoeira:

[...] Neste sentido, a roda de Capoeira é uma prática social, histórica, científica e política. Ela funciona como meio de formação de uma identidade cultural e de representações simbólicas de valores sociais para os seus atores. Nesse jogo de ataque e defesa, ela traz 
não só elementos contraditórios de reprodução de valores hegemônicos, mas, sobretudo, de superação desses valores porque, a todo tempo, leva o capoeirista a posicionar-se ante novos desafios sociais (CASTRO JÚNIOR, 2004, p. 149).

Mestre Magno se utiliza de um elemento que adquiriu significado no grupo para divulgar seu "projeto", ou seja, a palavra "leal/lealdade". Castro Júnior se apropria de estratégia semelhante, mas toma como instrumento legitimador de suas ideologias um ritual - a roda de Capoeira - , mesmo porque Castro Júnior não está transmitindo sua mensagem somente para um grupo específico de capoeiristas, e sim para a comunidade acadêmica da Educação Física. Observemos, também, que o articulista reconhece a presença da tensão entre valores contrapostos, mas que, de algum modo, "a roda" articula sua superação em face dos "novos desafios sociais".

Apesar de algumas semelhanças entre os discursos, ao compararmos a mensagem de Castro Júnior e a de Magno percebemos nuanças. Mestre Magno destacou em entrevista que poucos capoeiristas possuem a valorizada "lealdade", diferentemente do articulista, que afirma ser o praticante de Capoeira um sujeito compromissado socialmente e que supera os valores hegemônicos. Se, por um lado, Mestre Magno apresenta a racionalização sobre os valores da Capoeira, nem sempre internalizados pelos praticantes, por outro, Castro Júnior apresenta a Capoeira para a comunidade da Educação Física como um espaço cultural revolucionário. Essa distinção acontece porque os espaços nos quais os discursos estão sendo acionados são distintos. Ao veicular suas ideologias na RBCE, Castro Júnior busca legitimá-las perante um público que, em sua maioria, não vivencia a Capoeira; nesse caso, o periódico é um terreno adequado para elaboração de um discurso articulado segundo cânones disciplinares. Em outro cenário, Mestre Magno fala a língua dos praticantes, e veicula seus ideais por meio de símbolos específicos, como a "lealdade". A lealdade é uma figura central na estruturação dos grupos (HIRSCHMAN, 1973).

Outras características do grupo marcam suas diferenças no mundo da Capoeira e apontam uma relação bastante próxima com as ideias que transitam no ambiente acadêmico. De acordo com a visão dos professores e dos mestres, no grupo Humaitá

[...] os fundamentos pedagógicos são orientados no sentido de proporcionar ao aluno a compreensão crítica do contexto da Capoeira, bem como da sociedade como um todo.

O docente [...], ao assumir o papel de educador, no sentido amplo da palavra, e não apenas se comportando como um detentor de uma técnica corporal, estará comprometido com uma educação para a libertação. 
[Além disso,] o Grupo considera a Capoeira um patrimônio sócio-cultural universal e não um 'pacote' ou um 'remédio' para a cura de alguns males. (FALCÃO; VIEIRA, 1997, p. 45).

A palavra "libertação" potencializa o compromisso do professor de Capoeira com os ideais do grupo e com uma sociedade democrática, corroborando o mito que narra a Capoeira como uma "luta de liberdade". Nesse aspecto, o passado liga-se ao presente através de ideais, possibilitando uma continuidade temporal das manifestações da cultura. Os mestres transformam a Capoeira em pedagogia crítica.

Ainda focando esse trecho, insinua-se que o docente do Humaitá ensina uma Capoeira diferenciada, pois ela libertaria a mente do aluno para a reflexão do que ele aprende. A seguinte citação, veiculada na RBCE, elucida a proximidade dos discursos: "[a Capoeira constitui-se,] assim, como instrumento libertário de educação, permeado pelo forte espírito de brasilidade indispensável ao despertar e exercício crítico de cidadania" (SOUZA; OLIVEIRA, 1999, p. 1434).

Observemos que, tanto no campo acadêmico quanto no prático, os ideais e as ideologias buscam estabelecer e defender padrões e crenças de valor, conjugando-os a um passado ideal que confere uma certa "autenticidade" ao grupo Humaitá e à Capoeira. Desse modo, os atores sociais elaboram uma continuidade histórica artificial, que agencia o processo de invenção e manutenção das tradições (HOBSBAWN, 1997).

Participando dos treinos do grupo Humaitá, percebemos que o aprendizado da Capoeira envolve esquemas mentais e corporais interligados de tal forma, que se confundem com as capacidades morais e a vontade dos sujeitos. Esses esquemas são adquiridos por meio de repetições de movimentos, improvisos e vivências variadas. Contudo, para o sujeito se tornar "capoeirista", ele precisa apropriar-se também de elementos simbólicos que regem esse universo. Quando ensina Capoeira a seus alunos, a professora Júlia, do grupo Humaitá, destaca que eles devem soltar o corpo, sentir o ritmo; devem sentir a energia e viajar. Ela instrui: "Se você ficar muito preso na técnica do movimento, você não faz direito... Sabe... Aquela mandinga da Capoeira não vem! Se você se preocupar muito, a mandinga não vem!" (Diário de campo, 3 de julho de 2007).

A mandinga, ${ }^{7}$ vista pelos praticantes como uma energia que os move no jogo, é um elemento essencial que demarca a identidade da Capoeira frente a qualquer outra atividade corporal. A fala de Júlia pode ser comparada a este trecho da RBCE

7. "No mundo da Capoeira, ser mandingueiro é uma condição a ser adquirida e que distingue os capoeiristas. É ser manhoso, capaz de falsear a falsidade. O que [é] apreciado por jogar dominando os segredos e mistérios que o imaginário atribui ao jogo de Capoeira" (ABREU, 2005, p. I21). 
e elucidar, novamente, a proximidade dos discursos. Observemos que o articulista se utiliza de representações do ambiente prático para afirmar a Capoeira como cultura popular brasileira:

Realmente, a Capoeira sem mandinga perde a sua graça, sua referência cultural do povo. Aliás, perde o jeito brasileiro manhoso, lembrado no samba, no futebol e na música. A roda de Capoeira é um campo de mandinga, um campo astral, é um campo de energia [...] (CASTRO JÚNIOR, 2004, p. I54).

Devemos também abordar que alguns estudos acadêmicos sobre a Capoeira trazem discursos de denúncia contra forças unificadoras de natureza econômica e/ ou social geradas pelo processo de globalização. Nos artigos da RBCE analisados, identificamos críticas à esportivização, espetacularização e mercantilização da Capoeira, à mídia e, principalmente, ao capitalismo, visto como "vilão" que pode "descaracterizar" e/ou "empobrecer" esta prática corporal.

Constatamos ainda sugestões de uso da Capoeira como um dos instrumentos de luta contra as "imposições neoliberais". Essas sugestões justificam-se, em sua maioria, pela concepção de que essa atividade deveria manter o seu propósito "original", que é o da "resistência". Vieira, em artigo publicado na RBCE, apresenta sua visão, ao argumentar sobre a preponderância de gestos estereotipados na Capoeira moderna:

[...] Se há hegemonia de um determinado padrão estético, deve-se iniciar a construção de uma contra-hegemonia [...]. É importante que essa contra-hegemonia esteja fundamentada num indivíduo autônomo, consciente de seu corpo e de suas ações, não em outros clichês gestuais diferentes dos hegemônicos (VIEIRA, 1989, p. 62).

Analisando os dados coletados no trabalho de campo, percebemos que os ideais do grupo Humaitá também seguem uma perspectiva que busca romper com o capitalismo e a mercantilização da Capoeira. Exemplo disso são as intenções de disseminar uma Capoeira não violenta e desvinculada da obediência às regras e aos padrões, mostrando que o grupo caminha de modo diferente ao da Capoeira denunciada nas pesquisas acadêmicas.

Partindo desse princípio, criou-se no grupo Humaitá um evento chamado "Vem Sarobar". O nome do evento já é intrigante, pois existe uma representação no ambiente prático da Capoeira de que o capoeirista "saroba" é capoeirista "ruim". Um praticante nessa condição seria aquele que pratica uma Capoeira "desatualizada" (para alguns grupos de Capoeira, o "outro" quase sempre é "saroba"), que faz um jogo desprovido de beleza e/ou técnica, e que canta músicas que destoam do contexto. 
O evento "Vem Sarobar" é um momento em que os capoeiristas do grupo Humaitá se encontram para trocar ideias, assistir a vídeos de Capoeira, criar músicas e se divertir. Embora esse evento tenha um caráter recreativo - e até seja entendido pela maioria dos capoeiristas como tal -, seu principal objetivo é o de mudar essa representação de que alguém ou algum grupo deve ser taxado de "saroba" por não acompanhar o "padrão hegemônico" de se praticar Capoeira.

Ainda que o evento objetive divulgar a ideologia da "anti-hegemonia" de modo sutil, comprovamos que boa parte dos integrantes do grupo não adere ao movimento. Isso acontece por conflitos internos, gerados principalmente pela necessidade de demarcação e afirmação de poder entre os subgrupos. Portanto, esse evento parece contribuir mais para fortalecer alguns mecanismos sociais "hegemônicos" do que para contestá-los, estimulando a divisão entre os membros do grupo pela dominação, por alguns, daquele espaço/momento que se diz de todos.

Outros fatos demonstraram que, embora a proposta do Humaitá seja a de (re)criar uma Capoeira diferente da que é denunciada pelos estudiosos do tema, boa parte dos membros parece optar por acompanhar as condutas "hegemônicas". Os capoeiristas, mesmo afirmando seus vínculos às orientações e à filosofia do grupo, ajustam suas escolhas e ações a fim de suprir seus desejos de ascensão simbólica e social.

Identificamos que os praticantes adaptam a Capoeira a diferentes espaços sociais, buscando mais fatias de mercado. Essa expansão gera neles uma preocupação sobre o tipo de Capoeira que deve ser apresentada ao público e/ou aos "clientes". Em certa ocasião, um dos membros do Humaitá argumentava que, embora se deva valorizar o que público quer, ele não gostaria de apresentar uma Capoeira "espetacularizada", "descontextualizada", como fazem outros grupos. Assim, é possível perceber como membros do grupo aprofundam a construção de sua identidade a partir do "outro", afirmando que são diferentes, pois consideram a sua Capoeira "autêntica". Assim, uma prática "espetacularizada" é criticada como reducionista e mercantilizada.

Na construção da identidade nacional, um bem cultural é considerado patrimônio da nação ${ }^{8}$ quando é imbuído de autenticidade. Neste sentido, o autêntico é portador de uma "aura" de originalidade, de singularidade, e de uma relação genuína

8. Gonçalves (1988) explica que os patrimônios culturais, por serem elos entre o passado e o presente das nações, acabam por gerar sentimentos de vínculo de posse nos indivíduos. Esses sujeitos estabelecem uma "relação metonímica entre proprietário e propriedade e entre monumentos e passado". Sendo assim, "a propriedade [passa a ser considerada] parte do proprietário e vice-versa" (p. 267). 
com o passado que o envolve. Em contraposição, uma prática "espetacularizada" - reprodutora de gestos sem significados e de caráter transitório - não possui essa "aura", pois não guardam "[...] relação orgânica e real com um passado pessoal ou coletivo" (GONÇALVES, 1988, p. 265).

Sendo assim, vemos que a necessidade presente de resgate ou preservação da autenticidade da Capoeira demonstra a intenção do praticante em preservar a sua própria identidade. Seu discurso nos mostra que as subjetividades dos capoeiristas se constituem do mesmo modo que as identidades nacionalistas e elucida, novamente, uma visão bem próxima daquela identificada nos artigos veiculados na RBCE (ALMEIDA; TAVARES; SOARES, 2008).

A Capoeira possui uma espécie de ordem social alicerçada na tradição e, por esse motivo, seus atores sociais utilizam-se do passado, dos símbolos e da cultura oral como elementos fundamentais para sua constituição no presente. Segundo Almeida, Tavares e Soares (2008), os artigos publicados na RBCE traduzem a importância desses elementos como demarcadores da identidade cultural da Capoeira. Por meio da interpretação de alguns trechos, esses autores verificaram que o discurso dos articulistas assume um tom conservador, buscando preservar e exaltar tradições e elementos do passado, em detrimento às transformações que a Capoeira vem sofrendo.

No contexto dos grupos que dizem seguir um estilo mais "moderno", percebemos que as tradições têm valor, mas já não possuem tanta legitimidade em certas situações. Apesar de os praticantes saberem que têm um passado e o valorizarem, eles "não vivem cultuando este passado como forma de ausentar-se do presente, nem vivem mitificando [...] [cenas] que já estão por demais sacralizadas [...]" (OLIVEN, 2006, p. 182). A diferença entre os praticantes e os acadêmicos é que os praticantes parecem ser mais inovadores, pois se deixam influenciar pela contemporaneidade, e com isso dão à Capoeira uma flexibilidade identitária pertinente à dinâmica da modernidade. As mudanças que estão ocorrendo na Capoeira, mediante as influências dos sistemas modernos, "não implica[m] necessariamente a eliminação das categorias anteriormente contidas na estrutura simbólica, mas, sim, muitas vezes, uma readequação do conteúdo destas às novas exigências históricas" (BARBOSA, 2007, p. 182).

O discurso acadêmico também é marcado por um "espírito nacionalista". As estratégias discursivas utilizadas remontam à narrativa que foi sendo forjada para tornar a Capoeira um "símbolo nacional". Esse rótulo é utilizado como ferramenta para valorizá-la e legitimá-la em variadas situações. Além disso, o "popular" é diretamente relacionado à identidade nacional brasileira, acionado nas argumentações para aumentar o grau de autenticidade, pureza e até exotismo dessa atividade. A 
narrativa da Capoeira como cultura popular abarca um sentido de prática original de um povo "oprimido", que lutava por "nobres ideais" de resistência e/ou libertação.

As experiências do pesquisador de campo, identificado pelos praticantes mais como um "capoeirista sem grupo" do que como pesquisador, indicaram como esses atores sociais estruturam suas representações sobre a nação a partir da Capoeira e, consequentemente, como a Capoeira adquire os "traços" da brasilidade.

Algumas vezes o pesquisador de campo foi tratado com estranheza, indiferença e até desprezo por alguns capoeiristas que têm nos seus grupos fortes referências identitárias. Isto porque não ter vínculo com uma associação de Capoeira é como estar sem "bandeira", sem pátria, sem identidade. Nesse ambiente, o capoeirista sem grupo, sem mestre, corre o risco de ficar marginalizado, talvez por apresentar um comportamento tido como contrário ao valor de fidelidade. Ainda que esse pesquisador fosse conhecido pelos integrantes do Humaitá como "professor de Capoeira", em alguns eventos ele deixou de ser reconhecido como um "de dentro" por não estar vinculado a um grupo.

Constatamos que, hoje, os grupos de Capoeira funcionam como "comunidades", que produzem sentidos que se assemelham à "narrativa do nacional". Entretanto, verificamos que os capoeiristas acionam discursos identitários específicos que funcionam de maneira análoga aos discursos nacionalistas. Todavia, além desses discursos, eles manifestam traços "etnoculturais", que são considerados típicos da cultura brasileira (SCHNEIDER, 2004).

Neste cenário, os capoeiristas expressam condutas e discursos que nos levam a comprovar a existência de uma valorização de elementos do "nacional-popular". Alguns capoeiristas afirmam que os praticantes moradores de periferias possuem uma melhor "capacidade" para o jogo da Capoeira. Desse ponto de vista, os indivíduos provenientes das camadas populares portariam características que facilitariam a "incorporação" dos elementos simbólicos e gestuais dessa atividade.

[...] Nesse tempo, antes de começar o evento, pude conhecer outros Capoeiras do grupo e de fora. Conheci o tão falado professor Bruno do grupo Humaitá. Seu trabalho é bastante reconhecido pelos membros, e seus alunos jogam muito bem. Uma das justificativas dadas por alguns para a eficiência dos meninos de Bruno é que o trabalho é social, ou seja, se desenvolve com pessoas de classes sociais menos favorecidas (Diário de campo, 28 out. 2007).

9. O pesquisador de campo tinha experiência de I 5 anos com Capoeira. 
Percebemos que mostrar-se como portador de traços populares é um valor entre os capoeiristas. Dentro da roda, esses traços se configuram pelo "jeitinho" e "malandragem", ou seja, o jogo de cintura que o capoeirista deve ter para sair de situações difíceis, de forma semelhante ao "malandro carioca", figura representativa do modo de ser "brasileiro" (DAMATTA, 1983).

\section{CONCLUSÃO}

Diante das comparações e análises empreendidas, comprovamos a presença do processo reflexivo entre o campo acadêmico e o campo prático da Capoeira. Enquanto os articulistas se apropriam de elementos pertinentes ao ambiente prático da Capoeira para estruturar seus discursos, os praticantes, de modo estratégico, se apropriam de alguns signos acadêmicos para legitimar seus "projetos" e suas atividades.

Como explicamos, a apropriação constante do conhecimento gera um rompimento com modos de pensar e agir mais tradicionais. No entanto, o ambiente da Capoeira ainda é, predominantemente, dependente de simbologias tradicionais e de discursos essencializados. Isso demonstra o nível de reflexividade social baixo dessa atividade, quando comparada a outras práticas corporais modernas. Seus códigos e as condutas dos seus atores, embora demonstrem estar articulados, em alguma medida, aos processos de globalização, buscam mais a conservação e preservação de traços etnoculturais e de um passado "autêntico" como forma de legitimação.

Embora os discursos em questão apresentem certas disparidades quando comparados, identificamos que o sentido central deles é semelhante. Por meio de ideologias, projetos e/ou representações, ambos valorizam traços culturais de uma brasilidade forjada e reproduzem valores da tradição. Além de buscar realçar o "valor" singular da Capoeira nos mercados, essa tendência dos discursos também representa uma maneira de fortalecer os vínculos com a nação, em meio aos riscos e incertezas da modernidade.

Neste sentido, concluímos que a narrativa identitária da Capoeira se constrói por meio de uma reflexividade que se manifesta de modo incompleto, e que representa a realidade atual de um país que se encontra em processo de modernização, sem abrir mão das narrativas que exaltam a nação e sua constituição multicultural e étnica. 


\section{The reflexivity in the identity discourses of Capoeira}

ABSTRACT: It seems to be possible to show how the academic discourses about Capoeira, in the field of Physical Education, reaffirm essentialized and nationalistic myths and identities. Taking it for grant, the present study aims to demonstrate how the identity narratives on Capoeira are structured by "reflective processes". Using ethnographical methods, the identity discourses of a group of Capoeira were compared to academic discourses. We concluded that the identity narratives of Capoeira are structured by an incomplete reflexivity which reveals the process of modernization of the society and, therefore, the rebirth of the national.

KEYWORDS: Capoeira; identity; reflexivity; Physical Education

\section{La reflexividad en los discursos identitarios de la Capoeira}

RESUMEN: El discurso académico sobre la Capoeira, que circula en el campo de la Educación Física, reafirma identidades y mitos nacionalistas. Tomando como base esa afirmación, el estudio presente tiene como objetivo demostrar que en la actualidad las narrativas están estructuradas por procesos reflexivos. Por medio de métodos etnográficos, los discursos identitarios de un grupo de Capoeira fueron comparados a los de la esfera académica. Concluimos que esta reflexividad es incompleta, revelando el proceso de modernización de la sociedad $y$, consecuentemente, el renacer de la idea nacional.

PALABRAS-CLAVE: Capoeira; identidad; reflexividad; Educación Física.

\section{REFERÊENCIAS}

ABREU, F. J. Capoeiras: Bahia, Século XIX: imaginário e documentação. Salvador: Instituto Jair Moura, 2005.

ALMEIDA. J.; TAVARES, O.; SOARES, A. J. G. Discursos identitários da Capoeira na Revista Brasileira de Ciências do Esporte (RBCE). Revista Brasileira de Ciências do Esporte, v. 30, n. I , p. |7|-|85, set. 2008.

BARBOSA, A. M. e S. O futebol e a sociedade global: uma reavaliação da identidade sociocultural brasileira. Sociedade e Cultura, v. 10, n.2, 2007. Disponível em: < mww.revistas.ufg.br>. Acesso em: 24 jan. 2008.

CASTRO JÚNIOR, L. V. Capoeira Angola: olhares e toques cruzados entre historicidade e ancestralidade. Revista Brasileira de Ciências do Esporte, Campinas, v.25, n.2, p. I 43- I 58, jan. 2004. 
DAMATTA, R. Carnavais, malandros e heróis. 4. ed. Rio de Janeiro: Zahar, 1983.

FALCÃO, J. L. C.; VIEIRA, L. R. Capoeira: história e fundamentos do grupo Beribazu. Brasília: Starprint, 1997.

GIDDENS, A. Modernidade e identidade. Rio de Janeiro: Jorge Zahar, 2002.

GONÇALVES, J. R. Autenticidade, memória e ideologias nacionais: o problema dos patrimônios culturais. Estudos Históricos, Rio de Janeiro, v. I, n. 2, p. 264-275, 1988.

HALL, S. A identidade cultural na pós-modernidade. Rio de Janeiro: DP\&A, 2005.

HIRSCHMAN, A. Saída, voz e lealdade: reações ao declínio de firmas, organizações e Estados. São Paulo: Perspectiva, 1973.

HOBSBAWN, E.; RANGER, T. A invenção das tradições. Rio de Janeiro: Paz e Terra, 1997.

LUCAS, M. Zulu: idéias, ideais e ideário. Edição do Autor, 2002.

OLIVEN, R. G. A parte e o todo: a diversidade cultural no Brasil - nação. $2^{\mathrm{a}}$ ed., rev. e ampl. Petrópolis: Vozes, 2006.

SCHNEIDER, J. Discursos simbólicos e símbolos discursivos: considerações a sobre a etnografia da identidade nacional. Mana, Rio de Janeiro, v. I0, n. I, p. 97-129, abr. 2004. Disponível em: <www.scielo.br>. Acesso em: 2 fev. 2007.

SOUZA, S. A. R.; OLIVEIRA, A. A. B. A Capoeira da escola. Revista Brasileira de Ciências do Esporte, Florianópolis, v.21, n. I, p. 1434 , set. 1999.

TELLES, V. S. Pobreza e cidadania: dilemas do Brasil contemporâneo. Caderno CRH, Salvador, n. 19, p.8-21, jul./dez. 1993.

VELHO, G. O desafio da proximidade. In: ; KUSCHNIR, K. (Org.). Pesquisas urbanas: desafios do trabalho antropológico. Rio de Janeiro: Jorge Zahar, 2003. p. I I - 19.

VIEIRA, L. R. Criatividade e clichês no jogo da Capoeira: a racionalidade do corpo na sociedade contemporânea. Revista Brasileira de Ciências do Esporte, Campinas, v. I I, n. I , p. 58-63, set. 1989.

WACQUANT, L. J. D. Corpo e alma: notas etnográficas de um aprendiz de boxe. Tradução Angela Ramalho. Rio de Janeiro: Relume Dumará, 2002.

WHITE, W. F. Sociedade de Esquina. Rio de Janeiro: Jorge Zahar, 2005, p. 28I-377.

WOODWARD, K. Identidade e diferença: uma introdução teórica e conceitual. In: SILVA, T. T. (Org.). Identidade e diferença: a perspectiva dos estudos culturais. 5. ed. Petrópolis: Vozes, 2000. p. 7-55. 
Recebido: 16 abr. 2010 Aprovado: 5 jan. 2011

Endereço para correspondência: Antonio Jorge Gonçalves Soares Rua Alzira Cortes, 5, apto. 106 Botafogo Rio de Janeiro-RJ CEP: 22260-050 